\title{
Épocas de semeadura e desempenho agronômico de cultivares de soja
}

\author{
Giovane Vanin Meotti(1), Giovani Benin(1), Raphael Rossi Silva(2), Eduardo Beche(1) e Lucas Berger Munaro(1)
}

(1)Universidade Tecnológica Federal do Paraná, Campus Pato Branco, Rodovia do Conhecimento, Km 1, CEP $85503-390$ Pato Branco, PR. E-mail: giovane_vmt@hotmail.com, benin@utfpr.edu.br, eduardo_beche@hotmail.com, lucasbergermunaro@hotmail.com(2)Universidade Estadual de Londrina, Rodovia Celso Garcia Cid, Km 380, CEP 86051-980 Londrina, PR. E-mail: raphaelrossi@agronomo.eng.br

Resumo - O objetivo deste trabalho foi avaliar o efeito de épocas de semeadura no desempenho agronômico de cultivares de soja em São Domingos, SC, e indicar as cultivares mais estáveis e adaptadas a cada época. O experimento foi conduzido durante dois anos agrícolas (2008/2009 e 2009/2010), com seis cultivares e quatro épocas de semeadura (15/10,15/11, 15/12 e 15/1), em delineamento experimental de blocos ao acaso, com três repetições e parcelas com área útil de $3,6 \mathrm{~m}^{2}$. A metodologia AMMI (modelos de efeitos principais aditivos com interação multiplicativa) foi utilizada para avaliar o desempenho produtivo das cultivares, e a GGE (genótipo e interação genótipo $\mathrm{x}$ ambiente) para avaliar a adaptabilidade e a estabilidade das cultivares nas diferentes épocas de semeadura. Em ambos os anos agrícolas, as semeaduras em 15/10 e 15/11 maximizaram o número de vagens por planta, o número de grãos por vagem, a estatura das plantas, o número de ramos, a massa de mil sementes e, consequentemente, a produtividade de grãos. As cultivares de ciclo médio ou precoce com porte elevado são mais adequadas para semeaduras tardias.

Termos para indexação: Glycine max, AMMI, GGE biplot, interação genótipo x ambiente, produtividade de grãos.

\section{Sowing dates and agronomic performance of soybean cultivars}

\begin{abstract}
The objective of this work was to evaluate the effect of sowing dates on the agronomic performance of soybean cultivars in São Domingos, SC, Brazil, and to indicate stable and adapted cultivars for each sowing date. The experiment was carried out during two crop years (2008/2009 and 2009/2010), using six cultivars and four sowing dates $(10 / 15,11 / 15,12 / 15$, and 1/15), in a randomized complete block design, with three replicates and a usable plot area of $3.6 \mathrm{~m}^{2}$. The AMMI (additive main effects and multiplicative interaction analysis) method was used to evaluate the yield performance of the cultivars, and the GGE (genotype and genotype-by-environment) method to evaluate the adaptability and stability of the cultivars in each sowing date. In both crop years, the sowings on 10/15 and 11/15 maximized the number of pods per plant, the number of grains per pod, plant height, the number of branches, the weight of a thousand seeds, and, consequently, grain yield. Medium or early cycle cultivars, with high plant height, are more adequate for late sowing.
\end{abstract}

Index terms: Glycine max, AMMI, GGE biplot, genotype x environment interaction, grain yield.

\section{Introdução}

A soja [Glycine $\max ($ L.) Merril] é o principal cultivo no oeste catarinense, onde ocupa aproximadamente 216 mil hectares, o que corresponde a $61 \%$ da área cultivada com a cultura no estado (Síntese anual da agricultura de Santa Catarina, 2010). Nesta região, os riscos climáticos e os preços relativamente baixos na comercialização do trigo têm levado ao cultivo da soja em épocas não recomendadas.

A soja tem sido semeada precocemente para viabilizar o cultivo de milho safrinha. Além disso, temse observado a semeadura da soja safrinha, instalada em sucessão à cultura do milho (Peixoto et al., 2000;
Braccini et al., 2004). Contudo, em virtude das diferenças edafoclimáticas e do lançamento de novas cultivares, são necessários mais estudos regionalizados para que se possa avaliar melhor o efeito dos fatores ambientais no desenvolvimento das plantas de soja, nas diferentes épocas de semeadura.

O fotoperíodo e a temperatura, notadamente, exercem influência sobre o número de primórdios reprodutivos e a taxa de desenvolvimento, com reflexos sobre a estatura de planta, o ciclo e o potencial de produtividade da cultura (Braccini et al., 2004; Rodrigues et al., 2006; Jiang et al., 2011). Além disso, existe grande variabilidade entre as cultivares quanto à sensibilidade ao fotoperíodo e à temperatura, sendo que

Pesq. agropec. bras., Brasília, v.47, n.1, p.14-21, jan. 2012 
a primeira é considerada o principal fator determinante da adaptação das cultivares (Rodrigues et al., 2001b; Carvalho et al., 2002).

Dessa forma, a época de semeadura é fator preponderante para o sucesso da lavoura, pois resulta em alterações das relações hídricas, bem como, da temperatura, do fotoperíodo e da radiação solar disponíveis às plantas (Popp et al., 2002; Subedi et al., 2007). A semeadura tardia pode acarretar perdas da ordem de 30 a $50 \%$ na produtividade de grãos, enquanto semeaduras na época de safrinha podem causar perdas de até $70 \%$, em relação à época recomendada (Rodrigues et al., 2001a; Braccini et al., 2004; Rodrigues et al., 2008; Stülp et al., 2009). Portanto, a adoção de épocas de semeadura que propiciem condições climáticas próximas às exigidas pelas plantas é de extrema importância para um bom desempenho produtivo das lavouras (Peixoto et al., 2000).

Ao se considerar a dependência do ambiente para a expressão do genótipo, a análise da interação genótipo $x$ ambiente (IGA) é fundamental na avaliação de cultivares em diferentes ambientes. Entretanto, as diversas teorias para avaliar a adaptabilidade e a estabilidade das cultivares dificultam quanto à escolha do modelo estatístico a utilizar (Franceschi et al., 2010; Gouvêa et al., 2011). Diversos estudos comprovaram a eficiência da técnica biplot no entendimento da IGA(Yan \& Rajcan, 2002; Lee et al., 2003; Oliveira et al., 2003; Pacheco et al., 2009; Camargo-Buitrago et al., 2011). Neste contexto, as análises biplot AMMI (modelos de efeitos principais aditivos com interação multiplicativa) e GGE (genótipo e interação genótipo $\mathrm{x}$ ambiente) são eficientes para a avaliação de épocas de semeadura. Isso porque facilitam a interpretação da IGA, ao permitir a modelagem dos resultados em mais de uma dimensão, e são capazes de captar grande parte da variação do conjunto de dados quanto à importância relativa do genótipo e da IGA, além de permitirem visualização dos padrões de resposta dos genótipos (Roozeboom et al., 2008; Zhe et al., 2010).

O objetivo deste trabalho foi avaliar o efeito de épocas de semeadura no desempenho agronômico de cultivares de soja em São Domingos, SC, e indicar as cultivares mais estáveis e adaptadas a cada época.

\section{Material e Métodos}

$\mathrm{O}$ experimento foi instalado em sistema de plantio direto, em São Domingos, SC (26³3'19"S e $52^{\circ} 29^{\prime} 54^{\prime \prime} \mathrm{W}$, a $695 \mathrm{~m}$ de altitude). O solo da região é classificado como Latossolo Vermelho distroférrico (Santos et al., 2006), e o clima, conforme a classificação de Köppen, é do tipo $\mathrm{Cfb}$, subtropical úmido, com verão temperado.

Utilizou-se o delineamento experimental de blocos ao acaso, com três repetições, e os tratamentos foram distribuídos em esquema fatorial $2 \times 6 \times 4$ (safra, cultivares e épocas de semeadura, respectivamente). As parcelas consistiram de quatro linhas de 4,0 m de comprimento, com espaçamento de $0,45 \mathrm{~m}$ entre si. Foram considerados como parcela útil os $4,0 \mathrm{~m}$ centrais das duas fileiras internas, o que totalizou $3,6 \mathrm{~m}^{2}$. A semeadura foi realizada manualmente, com 12 a 18 sementes por metro. A adubação de base e os tratos culturais foram realizados de acordo com as recomendações técnicas para a cultura (Tecnologias de produção de soja, 2006).

Foram avaliadas seis cultivares de soja de diferentes grupos de maturação (GM), das quais três com hábito de crescimento indeterminado (BMX Apolo RR, $\mathrm{GM}=5,5$; BMX Energia RR, GM = 5,6; e BMX Força $\mathrm{RR}, \mathrm{GM}=6,2)$ e três com crescimento determinado (BRS 255 RR, GM = 6,7; BRS 294 RR, GM = 6,3; e BRS $295 \mathrm{RR}, \mathrm{GM}=6,5)$. As épocas de semeadura foram: 15/10 (E1), 15/11 (E2), 15/12 (E3) e 15/1 (E4), nos anos agrícolas de 2008/2009 e 2009/2010. Os dados meteorológicos das épocas do experimento estão descritos na Figura 1. Apenas E4 está fora do zoneamento de semeadura indicado para a região (Síntese anual da agricultura de Santa Catarina, 2010). Foi admitida a antecipação ou o atraso de dois a três dias em relação às datas de semeadura, quando as condições de umidade do solo foram limitantes ao plantio.

Foram avaliados os caracteres: altura de inserção da primeira vagem (IPV), estatura de planta (EP), número de ramificações (NR), número de vagens por planta (NVP), dias entre emergência e maturação (DEM), número de grãos por vagem (NGV), massa de mil sementes (MMS) e produtividade de grãos (PG). Os caracteres MMS e PG foram corrigidos para 13\% de umidade.

Os dados foram submetidos ao teste de Lilliefors e de Bartlett, para verificação da normalidade dos dados e da homogeneidade de variância, respectivamente. Uma vez que as variâncias foram normais e homogêneas, procederam-se às análises de variância, sem necessidade 
de transformação dos dados. Na análise conjunta, cultivares e épocas de semeadura foram consideradas como fatores fixos, e o ano foi considerado como fator aleatório. As análises foram realizadas pelo programa R (Development Core Team, 2009), utilizando-se o pacote Nortest para o teste de Lilliefors e o pacote Base para o teste de Bartlet e a análise de variância.

A adaptação das cultivares às épocas de semeadura foi avaliada por meio da metodologia AMMI1, que combina a análise de variância dos efeitos aditivos de genótipos e ambientes com a análise de componentes principais do efeito multiplicativo da interação genótipo x ambiente (Zobel et al., 1988), e do método GGE biplot, que considera o efeito do genótipo e da interação entre genótipos e ambientes (Yan et al., 2000). Ambas as análises foram realizadas com auxílio do aplicativo GGE biplot (Yan, 2001).
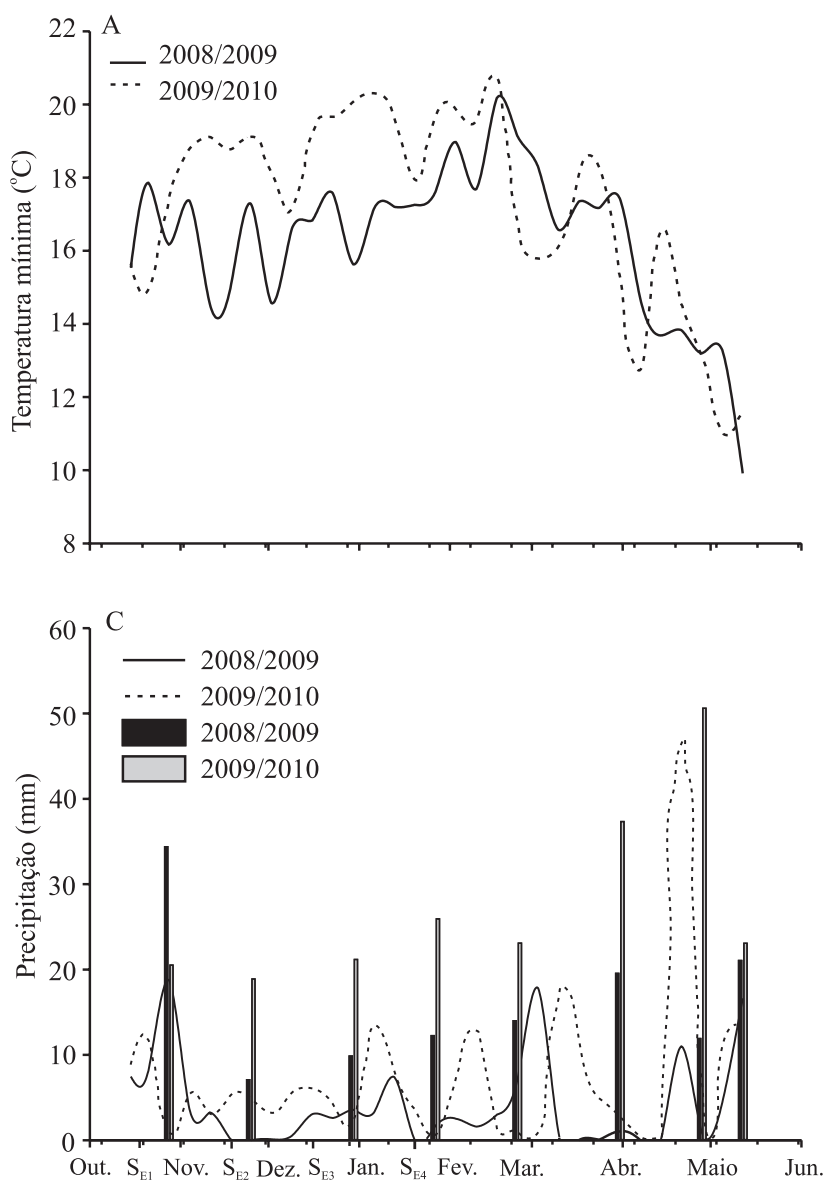

A interpretação das associações foi realizada pelo cosseno do ângulo entre os dois vetores a serem comparados. Foram adotados os seguintes critérios: a associação é positiva se o ângulo entre os vetores for $<90^{\circ}$; é negativa se o ângulo for $>90^{\circ}$; e é nula se o ângulo entre os vetores for igual a $90^{\circ}$ (Yan \& Tinker, 2006). A notação Transform $=0$ indica que os dados não foram transformados. A notação Scaling=0 indica que os dados não tiveram qualquer alteração. No entanto, no Scaling=1 (SD), cada valor é dividido pelo desvio-padrão de cada ambiente testado, o que mostra que os ambientes apresentam importância similar. A notação Centering, se refere ao modelo utilizado, em que: Centering $=0$ contém todos os efeitos, ou seja, genótipo, ambiente e interação genótipo $\mathrm{x}$ ambiente; e Centering=2 representa GGE - genótipo + interação genótipo x ambiente. O SVP ou "singular value partitioning" é uma técnica matemática para
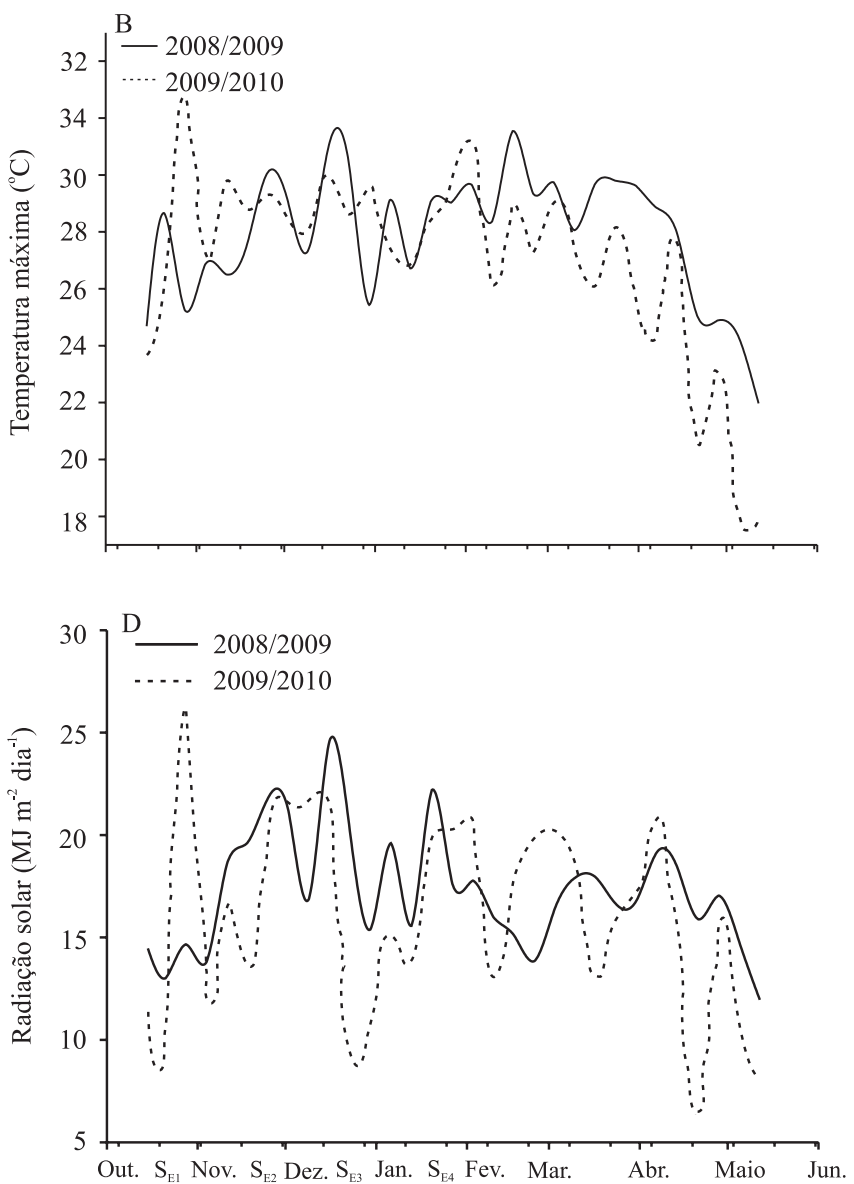

Figura 1. Dados meteorológicos médios semanais de temperatura mínima (A), temperatura máxima (B), precipitação pluvial (C) e radiação solar (D), nos anos agrícolas de 2008/2009 e 2009/2010, para as semeaduras realizadas em 15/10 (E1), 15/11 (E2), 15/12 (E3) e 15/1 (E4). Fonte: Instituto Tecnológico Simepar, 2010. 
decomposição de matrizes. O SVP=1, com foco na cultivar, foi utilizado para a análise da associação entre os caracteres agronômicos avaliados. $\mathrm{O} \mathrm{SVP}=2$, com foco no ambiente, foi utilizado para a identificação da melhor época de semeadura para cada cultivar, bem como da associação entre os caracteres agronômicos e as cultivares em estudo (Yan et al., 2000).

\section{Resultados e Discussão}

$\mathrm{Na}$ análise AMMI1 (Figura 2), observou-se variação total da PG pelo desdobramento dos efeitos principais de genótipo, ambiente e da interação entre ambos. A época de semeadura contribuiu com aproximadamente 79 e $74 \%$ da variação total em PG, nos anos agrícolas 2008/2009 e 2009/2010, respectivamente. $\mathrm{Na}$ análise conjunta, a combinação entre anos e épocas de semeadura explicou $77 \%$ da variação total. Estes resultados são indicativos de que a variação nas condições meteorológicas entre os anos (Figura 1) e o efeito das épocas de semeadura foram superiores ao efeito principal de cultivares e de interações. Em experimentos realizados em diferentes condições ambientais, $80 \%$ da variação na produtividade é causada, em geral, pelo ambiente, enquanto apenas $10 \%$ da variação ocorre em virtude dos efeitos de genótipos e da interação genótipo $\mathrm{x}$ ambiente (Yan, 2001; Asfaw et al., 2009).

Em ambos os anos agrícolas e na análise conjunta, o desempenho de PG nas épocas de semeadura E1 e E2 ficou acima da média geral, no gráfico biplot (indicado pelo centro das linhas perpendiculares na Figura 2). No entanto, as épocas de semeadura E3 e E4 foram agrupadas abaixo da média geral. Ao seguir a mesma interpretação, as cultivares com produtividade acima da média geral, em ordem decrescente, foram: BMX Força, BRS 295 e BMX Energia (2008/2009); BMX Apolo e BMX Energia (2008/2009); e BMX Energia, BMX Apolo, BMX Força e BRS 295 (análise conjunta).

A partição da IGA por meio da análise GGE biplot mostrou que os componentes principais (PC1 e PC2) representaram 85\% (2008/2009) e 94\% (2009/2010) da soma dos quadrados da IGA da produtividade de grãos (Figura 3). Esses valores conferem elevada confiabilidade à explicação da variação total pelo desempenho dos genótipos e sua interação com o ambiente $(\mathrm{G}+\mathrm{G} \times \mathrm{A})$. Assim, o desempenho produtivo das cultivares de soja nas diferentes épocas de semeadura pode ser explicado pelo padrão retido nas
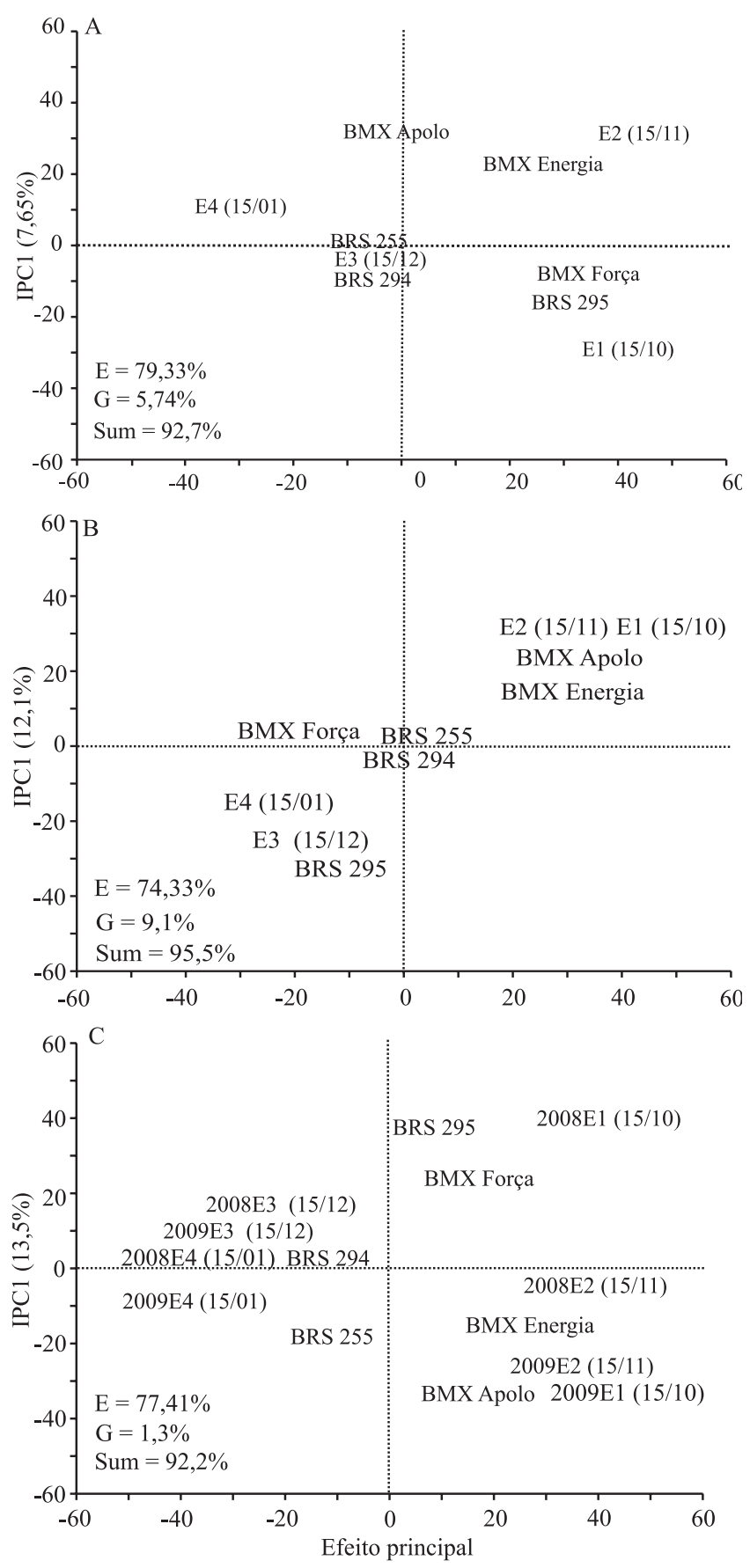

Figura 2. Plotagem dos escores do efeito principal de cultivares em função do primeiro componente principal (IPC1), conforme o modelo AMMI1, quanto à produtividade de grãos de seis cultivares de soja cultivadas em quatro épocas de semeadura (E1, E2, E3 e E4), nos anos agrícolas de 2008/2009 (A) e 2009/2010 (B), e de acordo com a análise conjunta $(\mathrm{C})$. 
análises gráficas (Morrison et al., 2008; Zhe et al., 2010).

Houve associação entre a PG das cultivares e as épocas de semeadura (Figura 3). Ângulos menores, maiores e iguais a $90^{\circ}$ graus indicam associação positiva, negativa e ausência de associação, respectivamente (Yan \& Tinker, 2006). Na safra de 2008/2009, as cultivares BRS 295 e BMX Força apresentaram associação positiva com a época de semeadura E1; BMX Energia, BMX Apolo e BRS 295 com E2; e BMX Força, BRS 295 e BRS 255 com E3 e E4. No ano agrícola de 2009/2010, observou-se o
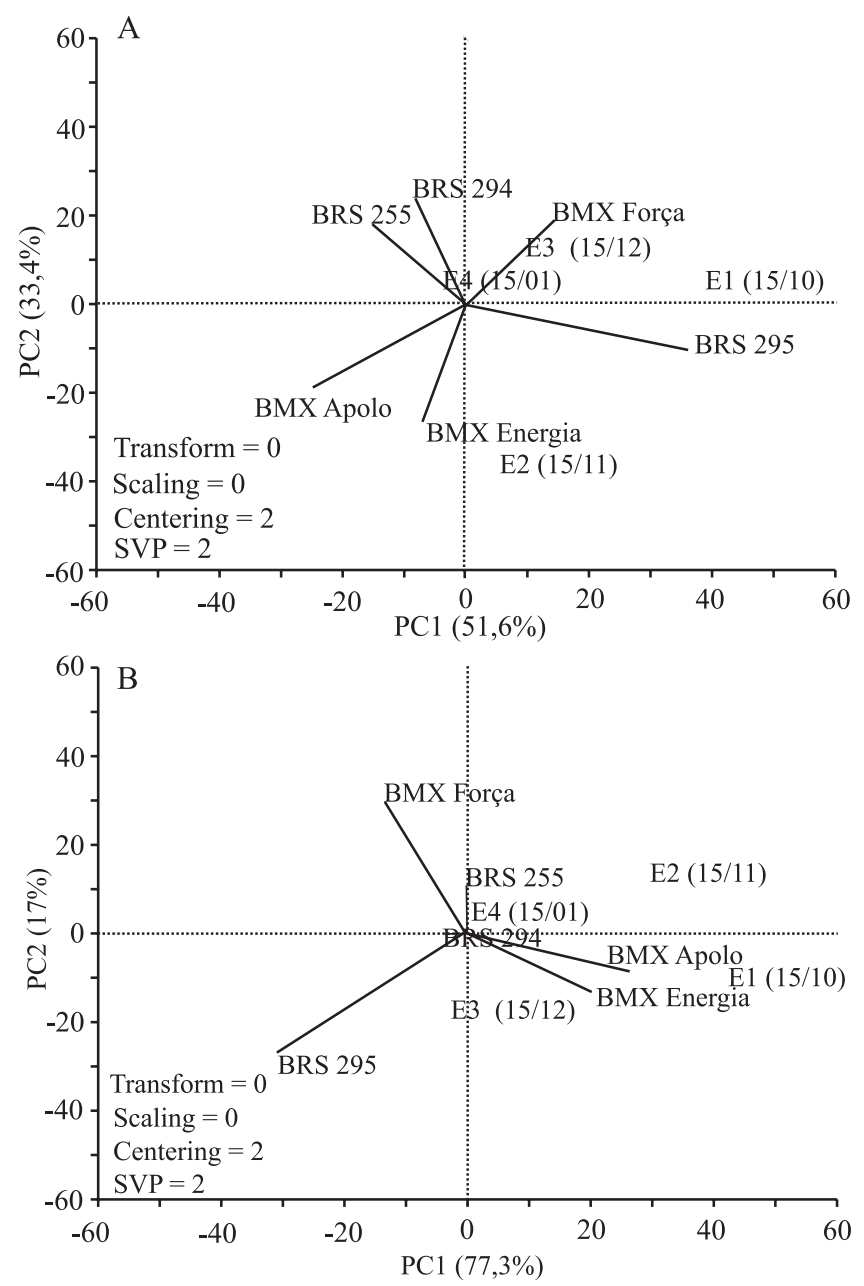

Figura 3. Plotagem dos escores dos componentes principais, quanto à associação entre épocas de semeadura e cultivares nos anos agrícolas de 2008/2009 (A) e 2009/2010 (B), conforme o modelo GGE biplot, para a variável produtividade de grãos de seis cultivares de soja, cultivadas em quatro épocas de semeadura (E1, E2, E3 e E4). seguinte padrão de associação entre cultivares e épocas de semeadura: BMX Apolo e BMX Energia (E1 e E2); BRS 255 e BMX Força (E2); BRS 295, BMX Energia e BMX Apolo (E3); e BRS 255, BMX Força e BRS 294 (E4). O efeito de anos de cultivo e épocas de semeadura no desempenho das cultivares (interação cruzada ou não previsível) pode ser atribuído, principalmente, a fatores como precipitação e temperatura (Figura 1), que foram mais elevados no ano agrícola de 2009 (Pereira et al., 2000; Anjos \& Nery, 2005).

Também foi observada associação entre as cultivares e os caracteres avaliados (Figura 4). A PG foi positivamente associada às cultivares BMX Força e BRS 295 (2008/2009) e BMX Energia e BMX Apolo (2009/2010). Nos dois anos, a MMS foi positivamente associada às cultivares BRS 294, BRS 255, BMXApolo e BMX Energia. As cultivares BMX Apolo e BMX Energia (ambos os anos) e BMX Força e BRS 295 (2009/2010) apresentaram o maior número de grãos por vagem. As cultivares BRS 294, BRS 255 e BRS 295 foram positivamente associadas a NR, DEM e NVP, em ambos os anos agrícolas. Da mesma forma, em ambos os anos, a EP e a IPV foram positivamente associadas às cultivares BMX Apolo e BRS 295. $\mathrm{O}$ ângulo agudo entre as projeções mostra que as variáveis avaliadas foram positivamente associadas às épocas de semeadura E1 e E2 (Figura 4), o que indica que elas são as melhores épocas para a maximização do potencial produtivo das cultivares avaliadas, o que confirma os resultados obtidos no presente trabalho (Figura 2).

Nas épocas de semeadura E1 e E2, as condições de temperatura, radiação solar e fotoperíodo favoreceram o desenvolvimento da cultura. Contudo, as semeaduras tardias (E3 e E4) foram submetidas a menor quantidade de radiação solar, temperaturas mais amenas e luminosidade insuficiente. Tais fatores contribuíram para o decréscimo na produtividade de grãos, como resultado da menor expressão de caracteres adaptativos e de componentes da produtividade de grãos (Rodrigues et al., 2001a, 2006).

Em semeaduras tardias, ocorreu florescimento precoce, redução do ciclo e da estatura de planta (Figura 4), bem como associação negativa entre DEM (E3 e E4) e EP (E4). Assim, quanto menor a duração da exposição das plantas a fotoperíodos longos, mais precoce será o florescimento quando a planta ainda apresenta baixo porte. Essas alterações 
na morfologia e na arquitetura da planta podem comprometer a produtividade de grãos (Jiang et al., 2011). Portanto, para o cultivo de soja em épocas de semeadura tardias, é importante adotar cultivares de
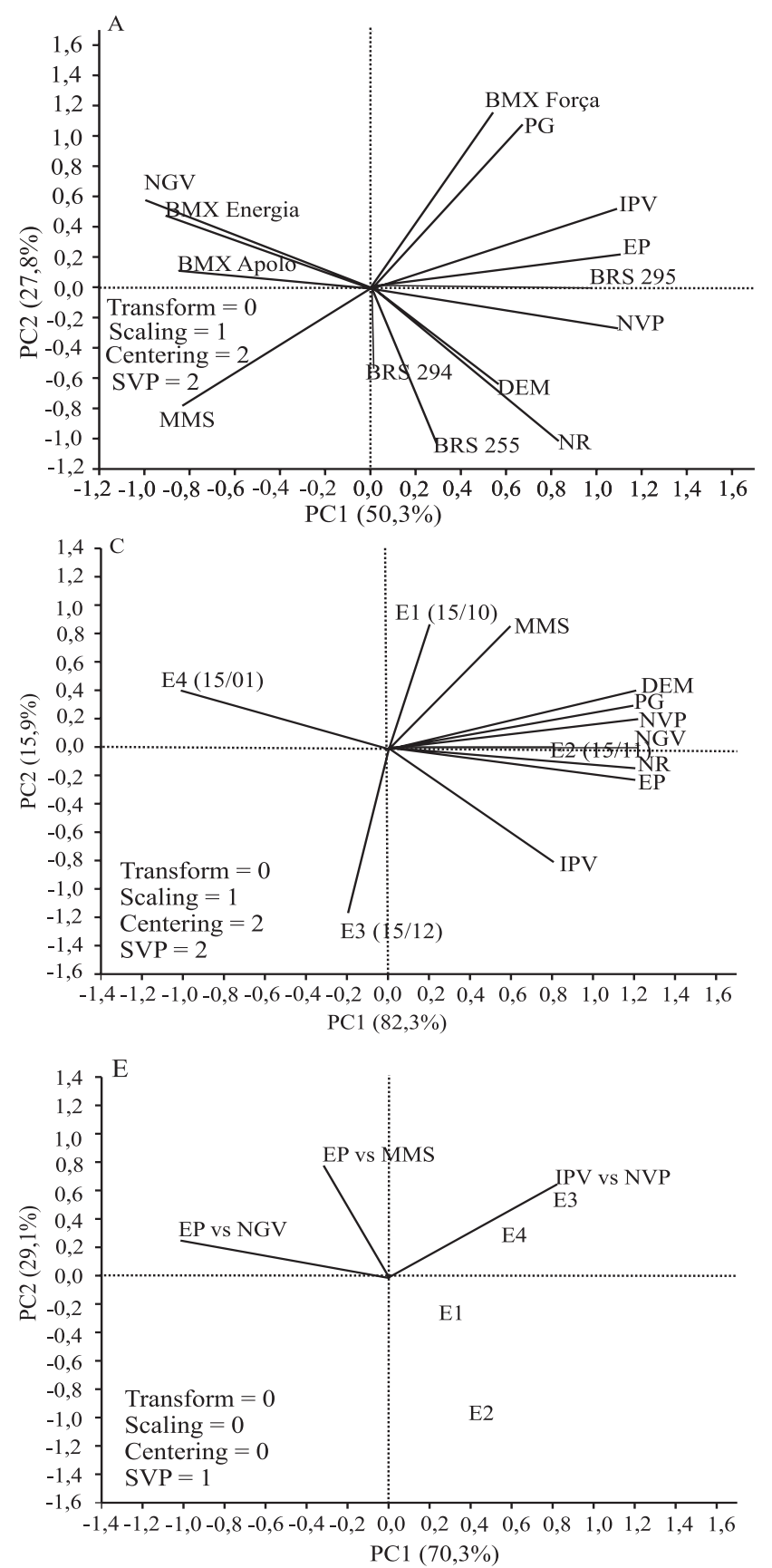

ciclo médio ou de ciclo precoce com porte elevado (Peixoto et al., 2000).

Observaram-se associações significativas entre os caracteres avaliados (Figura 4). Em ambos os anos
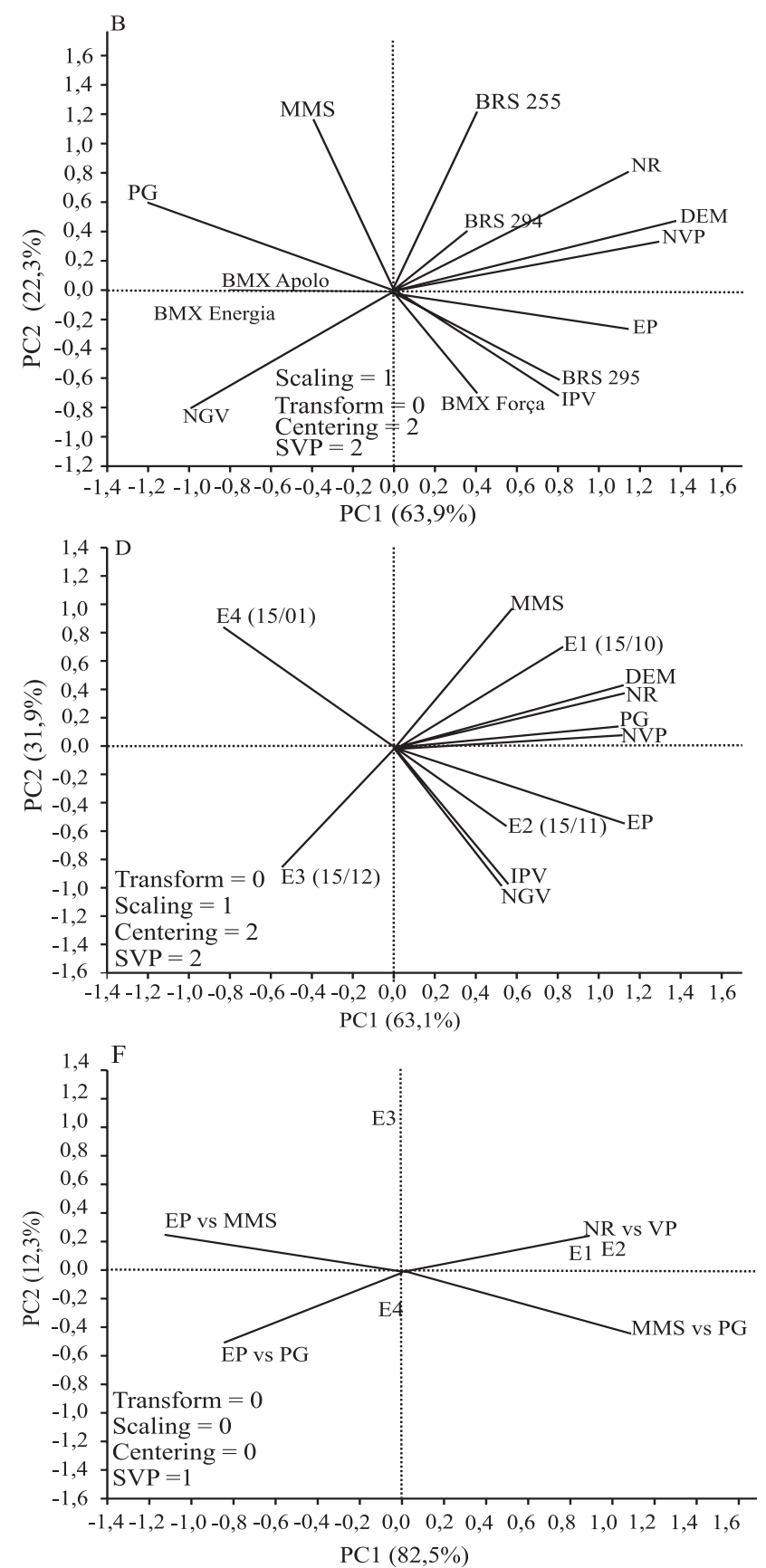

Figura 4. Plotagem dos escores dos componentes principais quanto às relações entre variáveis agronômicas e cultivares de soja nos anos agrícolas de 2008/2009 (A) e 2009/2010 (B); às relações entre variáveis agronômicas e épocas de semeadura nos anos agrícolas de 2008/2009 (C) e 2009/2010 (D), conforme o modelo GGE biplot; e à correlação entre as variáveis agronômicas nos anos agrícolas de 2008/2009 (E) e 2009/2010 (F), em quatro épocas de semeadura (E1, E2, E3 e E4). NGV, número de grãos por vagem; PG, produtividade de grãos; IPV, altura de inserção da primeira vagem; EP, estatura de planta; NVP, número de vagens por planta; DEM, dias entre emergência e maturação; NR, número de ramificações; MMS, massa de mil sementes.

Pesq. agropec. bras., Brasília, v.47, n.1, p.14-21, jan. 2012 
agrícolas, a redução na EP afetou negativamente MMS, NGV (2008/2009) e PG (2009/2010). Braccini et al. (2004) e Gubiani (2005) também observaram efeito negativo de épocas de semeadura tardias em PG e nos seus componentes. Porém, houve associação positiva entre IPV e NVP, no ano agrícola de 2008/2009, o que indica que a PG pode ser maximizada por meio da escolha de cultivares com maior altura de inserção de vagens. No ano agrícola de 2009/2010, em que as condições meteorológicas foram mais adequadas para o desenvolvimento da cultura, observou-se correlação positiva entre PG e MMS, e entre NR e NVP.

Assim, para o conjunto de cultivares avaliadas na região em estudo, deve-se dar preferência a épocas de semeadura próximas a $15 / 10$ e $15 / 11$, as quais apresentam condições climáticas mais favoráveis para o desenvolvimento da cultura. Semeaduras tardias (próximas a 15/12 e 15/1) afetaram negativamente o desempenho dos caracteres adaptativos, os componentes da produtividade e a PG das cultivares avaliadas. Independentemente do hábito de crescimento, em semeaduras tardias, são indicadas, preferencialmente, as cultivares BRS 255, BRS 294, BRS 295 e BMX Força, cujos grupos de maturação situam-se entre 6,2 e 6,7 .

\section{Conclusões}

1. Semeaduras realizadas na segunda quinzena de outubro e na primeira novembro, resultam em maior produtividade de grãos da cultura da soja.

2. Os componentes de produção apresentam ajustes, entre as cultivares, para compensar os efeitos da época de semeadura.

3. As cultivares de ciclo médio ou ciclo precoce, de porte elevado, são mais adequadas ao cultivo em épocas de semeadura tardias.

\section{Referências}

ANJOS, I.B. dos; NERY, J.T. Variáveis meteorológicas associadas ao rendimento de grãos no Estado do Paraná. Acta Scientiarum. Biological Sciences, v.27, p.133-144, 2005.

ASFAW, A.; ALEMAYEHU, F.; GURUM, F.; ATNAF, M. AMMI and SREG GGE biplot analysis for matching varieties onto soybean production environments in Ethiopia. Scientific Research and Essay, v.4, p.1322-1330, 2009.

BRACCINI, A. de L. e; MOTTA, I. de S.; SCAPIM, C.A.; BRACCINI, M. do C.L.; ÁVILA, M.R.; MESCHEDE, D.K. Características agronômicas e rendimento de sementes de soja na semeadura realizada no período de safrinha. Bragantia, v.63, p.81-92, 2004.

CAMARGO-BUITRAGO, I.; INTIRE, E.Q-Mc; GÓRDON-MENDOZA, R. Identificación de mega-ambientes para potenciar el uso de genotipos superiores de arroz en Panamá. Pesquisa Agropecuária Brasileira, v.46, p.1061-1069, 2011.

CARVALHO, C.G.P. de; ARIAS, C.A.A.; TOLEDO, J.F.F. de; OLIVEIRA, M.F. de; VELLO, N.A. Correlações e análise de trilha em linhagens de soja semeadas em diferentes épocas. Pesquisa Agropecuária Brasileira, v.37, p.311-320, 2002.

FRANCESCHI, L. de; BENIN, G.; MARCHIORO, V.S.; MARTIN, T.N.; SILVA, R.R.; SILVA, C.L. da. Métodos para análise de adaptabilidade e estabilidade em cultivares de trigo no Estado do Paraná. Bragantia, v.69, p797-805, 2010.

GOUVÊA, L.R.L.; SILVA, G.A.P.; SCALOPPI JUNIOR, E.J.; GONÇALVES, P. de S. Different methods to assess yield temporal stability in rubber. Pesquisa Agropecuária Brasileira, v.46, p.491-498, 2011.

GUBIANI, E.I. Crescimento e rendimento da soja em resposta a épocas de semeadura e arranjo de plantas. 2005. 77 p. Dissertação (Mestrado) - Universidade Federal do Rio Grande do Sul, Porto Alegre.

INSTITUTOTECNOLÓGICOSIMEPAR. Boletimpersonalizado. Disponível em: <www.simepar.br>. Acesso em: 10 set. 2010.

JIANG, Y.; WU, C.; ZHANG, L.; HU, P.; HOU, W.; ZU, W.; HAN, T. Long-day effects on the terminal inflorescence development of a photoperiod-sensitive soybean [Glycine $\max$ (L.) Merr.] variety. Plant Science, v.180, p.504-510, 2011.

LEE, S.J.; YAN, W.; AHN, J.K.; CHUNG, I.M. Effects of year, site, genotype and their interactions on various soybean isoflavones. Field Crops Research, v.81, p.181-192, 2003.

MORRISON, M.J.; COBER, E.K.; SALEEM, M.F.; MCLAUGHLIN, N.B.; FREGEAU-REID, J.; MA, B.L.; YAN, W.; WOODROW, L. Changes in isoflavone concentration with 58 years of genetic improvement of short-season soybean cultivars in Canada. Crop Science, v.48, p.2201-2208, 2008.

OLIVEIRA, A.B. de; DUARTE, J.B.; PINHEIRO, J.B. Emprego da análise AMMI na avaliação da estabilidade produtiva em soja. Pesquisa Agropecuária Brasileira, v.38, p.357-364, 2003.

PACHECO, R.M.; DUARTE, J.B.; SOUZA, P.I.M. de; SILVA, S.A. da; NUNES JUNIOR, J. Key locations for soybean genotype assessment in Central Brazil. Pesquisa Agropecuária Brasileira, v.44, p.478-486, 2009.

PEIXOTO, C.P.; CÂMARA, G.M. de S.; MARTINS, M.C.; MARCHIORI, L.F.S.; GUERZONI, R.A.; MATTIAZZI, P. Épocas de semeadura e densidade de plantas de soja: componentes da produção e rendimento de grãos. Scientia Agrícola, v.57, p.47-61, 2000.

PEREIRA, E.B.C.; PEREIRA, A.V.; FRAGA, A.V. Qualidade de sementes de cultivares precoces de soja produzidas em três épocas. Pesquisa Agropecuária Brasileira, v.35, p.1653-1662, 2000.

POPP, M.O.; KEISLING, T.C.; MCNEW, R.W.; OLIVER, L.R.; DILLON, C.R.; WALLACE, D.M. Planting date, cultivar, and

Pesq. agropec. bras., Brasília, v.47, n.1, p.14-21, jan. 2012 
tillage system effects on dryland soybean production. Agronomy Journal, v.94, p.81-88, 2002.

R DEVELOPMENT CORE TEAM. R: a language and environment for statistical computing. Vienna: R Foundation for Statistical Computing, 2009.

RODRIGUES, O.; DIDONET, A.D.; LHAMBY, J.C.B.; BERTAGNOLLI, P.F. Rendimento de grãos de soja em resposta à época de semeadura. Passo Fundo: Embrapa Trigo, 2001. 3p. (Embrapa Trigo. Comunicado técnico online, 65).

RODRIGUES, O.; DIDONET, A.D.; LHAMBY, J.C.B.; BERTAGNOLLI, P.F.; LUZ, J.S. da. Resposta quantitativa do florescimento da soja à temperatura e ao fotoperíodo. Pesquisa Agropecuária Brasileira, v.36, p.431-437, 2001b.

RODRIGUES, O.; DIDONET, A.D.; LHAMBY, J.C.B.; TEIXEIRA, M.C.; GUARESCHI, R. Efeito da temperatura e do fotoperíodo na duração e na taxa de crescimento de grãos de soja. Passo Fundo: Embrapa Trigo, 2006. 28p. (Embrapa Trigo. Boletim de pesquisa e desenvolvimento online, 35).

RODRIGUES, O.; TEIXEIRA, M.C.C.; COSTENARO, E.R.; AVOZANI, A. Rendimento de grãos de soja em semeadura tardia. Passo Fundo: Embrapa Trigo, 2008. 26p. (Embrapa Trigo. Boletim de pesquisa e desenvolvimento Online, 66).

ROOZEBOOM, K.L.; SCHPAUGH, W.T.; TUINSTRA, M.R.; VANDERLIP, R.L.; MILLIKEN, G.A. Testing wheat in variable environments: genotype, environment, interaction effects, and grouping test locations. Crop Science, v.48, p.317-330, 2008.

SANTOS, H.G. dos; JACOMINE, P.K.T.; ANJOS, L.H.C. dos; OLIVEIRA, V.A. de; OLIVEIRA, J.B. de; COELHO, M.R.; LUMBRERAS, J.F.; CUNHA, T.J.F. (Ed.). Sistema brasileiro de classificação de solos. 2.ed. Rio de Janeiro: Embrapa Solos, 2006. $306 \mathrm{p}$.
SÍNTESE anual da agricultura de Santa Catarina: 2010-2011. Florianópolis: Epagri, 2011. 315p. Disponível em: <http://cepa. epagri.sc.gov.br/>. Acesso em: 25 mar. 2011.

STÜLP, M.; BRACCINI, A.L. de; ALBRECHT, L.P.; ÁVILA, M.R.; SCAPIM, C.A.; SCHUSTER, I. Desempenho agronômico de três cultivares de soja em diferentes épocas de semeadura em duas safras. Ciência e Agrotecnologia, v.33, p.1240-1248, 2009.

SUBEDI, K.D.; MA, B.L.; XUE, A.G. Planting date and nitrogen effects on grain yield and protein content of spring wheat. Crop Science, v.47, p.36-47, 2007.

TECNOLOGIAS de produção de soja - região central do Brasil 2007. Londrina: Embrapa Soja, 2006. 225p. (Embrapa Soja. Sistemas de produção, 11).

YAN, W. GGE biplot - a Windows application for graphical analysis of multienvironment trial data and other types of two-way data. Agronomy Journal, v.93, p.1111-1118, 2001.

YAN, W.K.; HUNT, L.A.; SHENG, Q.L.; SZLAVNICS, Z. Cultivar evaluation and mega-environment investigation based on the GGE biplot. Crop Science, v.40, p.597-605, 2000.

YAN, W.; RAJCAN, I. Biplot analysis of test sites and trait relations of soybean in Ontario. Crop Science, v.42, p.11-20, 2002.

YAN, W.; TINKER, N.A. Biplot analysis of multi-environment trial data: principles and applications. Canadian Journal of Plant Science, v.86, p.623-645, 2006.

ZHE, Y.; LAUER, J.G.; BORGES, R.; LEON, N. Effects of genotype $\mathrm{x}$ environment interaction on agronomic traits in soybean. Crop Science, v.50, p.696-702, 2010.

ZOBEL, R.W.; WRIGHT, M.J.; GAUCH, H.G. Statistical analysis of a yield trial. Agronomy Journal, v.80, p.388-393, 1988.

Recebido em 13 de setembro de 2011 e aprovado em 19 de dezembro de 2011 